\title{
Biochemical composition and antioxidant capacity of extracts from Podophyllum hexandrum rhizome
}

\author{
Mengfei Li, Lanlan Zhou, Delong Yang, Tiantian Li and Wei Li
}

\begin{abstract}
Background: Podophyllum hexandrum Royle (P. hexandrum) is a perennial herb and widely used in clinic. The present study was designed to separate and identify the biochemical composition and antioxidant capacity of extracts from $P$. hexandrum rhizome.

Methods: The ethyl acetate and ethanol extracts from $P$. hexandrum rhizome were analyzed by GC-MS (gas chromatography-mass spectrometry), and the antioxidant capacity of the extracts and the components was tested by using the DPPH (2, 2-diphenylpicrylhydrazyl) and FRAP (Ferric reducing/antioxidant power) assays.

Results: The rhizome extracts had greater antioxidant capacity than the petiole extracts in DPPH and FRAP assays. About 16 kinds of main reactive oxygen components were identified in the extracts. Components of PADE (Phthalic acid, diisobutyl ester), BADE (1,2-Benzenedicarboxylic acid, diisooctyl ester), Polyneuridine, PODD (Podophyllotoxin, deoxy), $\beta$-Sitosterol and POD (Podophyllotoxin) showed the antioxidant capacity in some degree. PODD, POD, and Polyneuridine showed stronger antioxidant capacity with the $I_{50}$ and FRAP values of $9.61 \pm 0.81$ and $2923.98 \pm$ $21.89 \mu \mathrm{M}, 9.98 \pm 0.24$ and $2847.27 \pm 14.82 \mu \mathrm{M}$, and $13.37 \pm 0.35$ and $2404.32 \pm 36.88 \mu \mathrm{M}$, respectively, than the positive control ASA (Ascorbic acid) with the values of $60.78 \pm 1.22$ and $1267.5 \pm 30.24 \mu \mathrm{M}(P<0.01$ ).
\end{abstract}

Conclusions: PODD, POD, and Polyneuridine are very critical for the antioxidant capacity in the extract of $P$. hexandrum rhizome. These results provide useful biochemical basis and information for the potential use of this plant.

Keywords: Podophyllum hexandrum, Biochemical composition, Antioxidant capacity, GC-MS

\section{Background}

Podophyllum hexandrum Royle (P. hexandrum), commonly named Himalayan Mayapple, is a perennial herb that grows in the Himalayan region and the southwest of China [1,2]. Since 1940 P. hexandrum resin has been used topically for various skin lesions such as warts and condylomas [3]. POD is a natural product mainly existing in P.hexandrum rhizome. It has been used in the treatment of genital infection to sterilize noncervical human papilloma virus [4]. Penile warts can be safely treated with $0.5-2.0 \%$ podophyllin self applied [5]. Goel et al. [6] reported a significant antitumour effect at

\footnotetext{
*Correspondence: liwei@gsau.edu.cn

Gansu Provincial Key Lab of Aridland Crop Science / College of Life Science and Technology, Gansu Agricultural University, Lanzhou 730070, Gansu, P.R. China
}

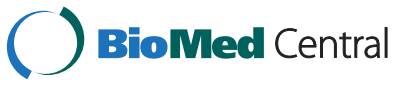

(c) 2012 Li et al.; licensee BioMed Central Ltd. This is an Open Access article distributed under the terms of the Creative Commons Attribution License (http://creativecommons.org/licenses/by/2.0), which permits unrestricted use, distribution, and reproduction in any medium, provided the original work is properly cited. subtoxic, well-tolerated, sequential doses of aqueous extract of $P$. hexandrum. POD is also used as starting compound for the chemical synthesis of etoposide (VP16-213) and teniposide (VM-26), and its congeners and derivatives have pronounced biological activity as anticancer, antineoplastic and anti-HIV drugs [7-9]. Researchers have recently paid attention to the antioxidant activity of POD and its derivatives, such as GP7OH, GP7H, GP7 and VP16 [10]. So far, there is no specific study on the biochemical composition and the antioxidant capacity of P.hexandrum rhizome extracts. In our previous study, GC-MS showed that the ethyl ether extract of $P$. hexandrum seed contained some bioactive components, such as Hexanedioic acid, Oleic acid, and Octadecanoic acid [11]. 
In the present study, we tested the antioxidant capacity of ethyl acetate and ethanol extracts in the rhizome and petiole of P.hexandrum by the DPPH and FRAP assays, separated and identified the biochemical compositions of the rhizome extracts by GC-MS, and then evaluated antioxidant capacity of some identified compositions with the parameters of $\mathrm{IC}_{50}$ and FRAP value.

\section{Methods}

\section{Plant materials}

$P$. hexandrum was collected from a forest $(2,100 \mathrm{~m})$ in HuiChuan, WeiYuan of Gansu Province, China, after the plant fruit ripened in September 2011. The plant was dried in shade under room temperature. The species was identified by Professor Yanling Qi (Gansu Provincial Academy of Agricultural Sciences, Lanzhou, Gansu, P.R.China). A voucher specimen (No.0209069) was deposited in the herbarium of College of Agronomy, Gansu Agricultural University, Lanzhou, Gansu, P.R. China.

\section{Reagents and instrumentation}

$\mathrm{DPPH}, 2$, 4, 6-tris (2-pyridyl)-s-triazine (TPTZ), PADE, BADE, Polyneuridine, PODD, $\beta$-Sitosterol, and POD were purchased from Sigma Chemical Company (St. Louis, MO, USA). Ethyl acetate, ethanol, methanol, ASA, $\mathrm{FeCl}_{3} \cdot 6 \mathrm{H}_{2} \mathrm{O}$, and $\mathrm{HCl}$ were purchased from Guangfu Chemical Research Institute (Tianjin, P.R. China). UV-1810 (Beijing Persee General Instrument Co., Ltd, P.R.China) and Trace DSQ GC-MS (American Finnigan Company, USA) were used.

\section{Preparation of extracts}

Rhizome and petiole were washed, dried and grinded to powder. Then the powder was weighted $(20.00 \mathrm{~g})$ and soaked in ethyl acetate and ethanol $(500 \mathrm{mg} / \mathrm{mL})$ for 10 months at room temperature in dark, and was then filtered, evaporated and condensed to dryness under nitrogen to obtain extracts.

\section{Antioxidant assays}

Although there are numerous methods for determining the antioxidant capacity of soluble natural extracts and insoluble food components [12], no perfect system is available to help us know the "true" antioxidant capacity of a complex medium [13,14]. The DPPH and FRAP assays, despite their disadvantages, are still used by many researchers for rapid evaluation of antioxidant [15].

\section{DPPH assay}

The free radical scavenging activity (FRSA) of DPPH was measured according to Ramadan et al. [16] and
Nencini et al. [17]. which is one of the few stable and commercially available organic nitrogen radical assays $[18,19]$. Foti et al. [20] suggested it is an electron transfer reaction. The initial electron transfer occurs very quickly, while the subsequent hydrogen transfer occurs more slowly and depends on the hydrogen-bond accepting solvent $[18,19]$. This reaction has been measured by the decoloration assay where DPPH has an absorption band at $515 \mathrm{~nm}$ which disappears upon reduction by an antiradical compound $[18,21]$. The specific steps are as follows.

The extracts were diluted with $15 \%$ aqueous ethanol with concentration of $10 \mathrm{mg} / \mathrm{mL}$, and then $50 \mu \mathrm{L}$ of the diluted extracts was added with $950 \mu \mathrm{L}$ of $10^{-4} \mathrm{M}$ DPPH methanol solution. Then the mixture was shaken and kept in dark for $30 \mathrm{~min}$ at room temperature. The decreased absorbance of DPPH solution was evaluated at $515 \mathrm{~nm}$ by a spectrophotometer UV-1018, and $500 \mu \mathrm{M} \mathrm{15 \%}$ aqueous ethanol ASA was tested as a positive control. The test was carried out in triplicate, and the capability to scavenge the DPPH radicals was calculated as:

$$
\begin{aligned}
& \text { Scavenging effect }(\mathrm{I} \%, \text { Percentage of inhibition }) \\
& \quad=\left[\left(A_{0}-A\right) / A_{0}\right] \times 100
\end{aligned}
$$

where $A_{0}$ and $A$ were the absorbance of DPPH without and with sample, respectively.

\section{FRAP assay}

The FRAP test was first introduced by Benzie et al. [22] for measuring the total antioxidant activity, which was initially developed to assay plasma antioxidant capacity but can also be used on other fluids. In the FRAP test, reductants (antioxidants) in the sample reduce ferric-tripyridyltriazine complex $\left(\mathrm{Fe}^{3+}-\mathrm{TPTZ}\right)$, in stoichiometric excess, to a blue ferrous form $\left(\mathrm{Fe}^{2+}\right)$, with an increase in absorbance at $593 \mathrm{~nm}$ [17]. The specific steps were described by Tsao et al. [23] as follows.

The working FRAP reagent was prepared ex tempore by mixing 10 volumes of $300 \mathrm{mmol} / \mathrm{L}$ acetate buffer, $\mathrm{pH}$ 3.6, with $10 \mathrm{mmol} / \mathrm{L}$ TPTZ in $40 \mathrm{mmol} / \mathrm{L} \mathrm{HCl}$, and $20 \mathrm{mmol} / \mathrm{L} \mathrm{FeCl}_{3} \cdot 6 \mathrm{H}_{2} \mathrm{O}$ at 10:1:1 (v/v/v).

The $300 \mu \mathrm{L}$ FRAP reagent and the $10 \mu \mathrm{L}$ standard samples $\left(\mathrm{FeSO}_{4} \cdot 7 \mathrm{H}_{2} \mathrm{O}, 500 \mu \mathrm{M}\right)$ or test samples (10 $\mathrm{mg} / \mathrm{mL} 15 \%$ aqueous ethanol) were added and mixed well. The reaction temperature was $37^{\circ} \mathrm{C}$ and the absorbance readings were taken at $593 \mathrm{~nm}$ immediately and 4 min later using a spectrophotometer UV1018. And $500 \mu \mathrm{M} 15 \%$ aqueous ethanol ASA was tested as a positive control. All tests were carried out in triplicate. The FRAP value of the test samples was 
calculated on the basis of $500 \mu \mathrm{M} \mathrm{Fe} e^{2+}\left(\mathrm{FeSO}_{4} \cdot 7 \mathrm{H}_{2} \mathrm{O}\right)$ as follows:

FRAP value $(\mu \mathrm{M})=$

$\left(\ddot{\mathrm{A}} A_{593 n m}\right.$ test sample $/ \ddot{\mathrm{A}} A_{593 n m}$ standard sample $\times 500(\mu \mathrm{M})$

where $\ddot{A} A_{593 n m}$ was the absorbance of the sample minus the absorbance of the blank at the 4th minute.

\section{GC-MS analysis}

The samples were the rhizome extracts of ethyl acetate and ethanol $(500 \mathrm{mg} / \mathrm{mL})$. Trace DSQ GC-MS from American Finnigan Company was used. The GC conditions were: $1 \mathrm{~N}$ NOWAX quartz capillary column: $30 \mathrm{~m} \times 0.32 \mathrm{~cm} \times 0.25 \mathrm{~mm}$; column temperature: $50-190^{\circ} \mathrm{C}$; procedure temperature: $5^{\circ} \mathrm{C} / \mathrm{min}$; carrier gas: $\mathrm{He}$; vaporizer temperature: $280^{\circ} \mathrm{C}$; the MS conditions were: Ion source: $\mathrm{EI}$; temperature: $200^{\circ} \mathrm{C}$; ionizing voltage: $70 \mathrm{eV}$; electric current of collection: $300 \mu \mathrm{A}$; electric current of emission: $1 \mathrm{~mA}$; resolution: 600; mass: $10-600$.

\section{Evaluation of antioxidant assays}

Reagents PADE, BADE, Polyneuridine, PODD, $\beta$ Sitosterol, POD, and including the positive control ASA were dissolved in $15 \%$ aqueous ethanol and tested at the same concentration of $500 \mu \mathrm{M}$. Antioxidant capacity was expressed $\mathrm{IC}_{50}(\mu \mathrm{M})$ and FRAP $(\mu \mathrm{M})$ and the test methods were mentioned above (as the DPPH and FRAP assays).

\section{Statistical analysis}

The results were presented as mean $\pm \mathrm{SD}$ of triplicate determinations. Statistical analysis was performed by SPSS 11.5. One-way analysis of variance (ANOVA) was utilized to evaluate differences.

\section{Results}

Antioxidant capacity of rhizome and petiole extracts

FRSAs from the rhizome and petiole extracts of $P$. hexandrum expressed as I \% are showed in Figure 1, and the antioxidant capacity expressed as FRAP value is reported in Figure 2. FRSAs of ethyl acetate and ethanol extracts were higher from the rhizome $(90.17 \pm 1.11$ and $94.52 \pm 0.17 \%$, respectively) than from the petiole $(68.75 \pm 0.52$ and $77.23 \pm 1.01 \%$, respectively). The FRAP values showed the same trend as FRSAs, and the FRAP values of ethyl acetate and ethanol extracts from the rhizome were $1784.09 \pm 52.07$ and $2079.55 \pm 34.09 \mu \mathrm{M}$, and the values of the petiole were $420.45 \pm 85.79$ and $886.36 \pm 68.18 \mu \mathrm{M}$. In both DPPH and FRAP assays, $500 \mu \mathrm{M}$ ASA was tested as a positive control, and the values of I\% and FRAP value were $88.25 \pm 0.24 \%$ and $1267.5 \pm 30.24 \mu \mathrm{M}$, respectively. The statistical

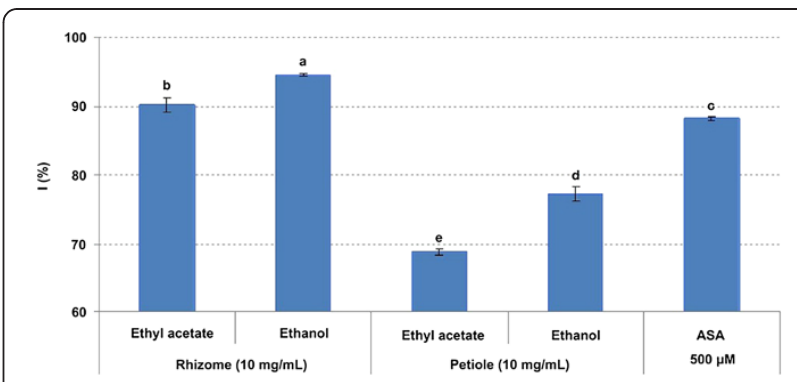

Figure 1 I \% of extracts from $P$. hexandrum measured by the DPPH assay. ASA was tested as a positive control. The data are the mean of triplicate measurements. Different letters on top of the column were considered significant at $p<0.01$.

analyses showed that the rhizome extracts had greater antioxidant capacity than the petiole extracts and the ethanol extracts had greater antioxidant capacity than the ethyl acetate extract both in DPPH and FRAP assays $(p<0.01)$.

\section{Separation and identification of rhizome extracts}

In order to further study the biochemical compositions in $P$. hexandrum rhizome, the extracts of the ethyl acetate and ethanol were separated and identified by GCMS. In total, About 16 kinds of reactive oxygen were identified. The compound retain time (RT), name, molecular formula, molecular weight, area and percentage of area (POA) were listed in Table 1 (the ethyl acetate extract) and Table 2 (the ethanol extract), and the compound structures were presented in Figure 3 (the ethyl acetate extract) and Figure 4 (the ethyl acetate extract).

The ethyl acetate and ethanol extracts contained five common components: PADE, BADE, PODD, $\beta-$ Sitosterol, POD, and the POA of the five components in the ethyl acetate and ethanol extracts were 2.77 and $1.23,2.25$ and $7.05,20.59$ and 20.97, 1.61 and 1.22, 67.41 and $22.73 \%$, respectively. The Polyneuridine also showed the high POA with $28.01 \%$ in the ethanol extract.

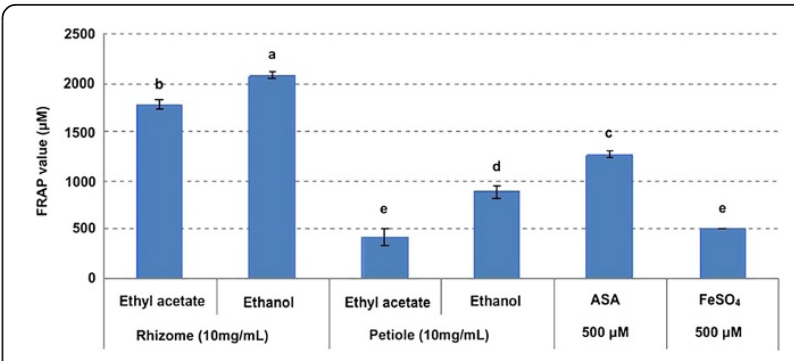

Figure 2 FRAP value of extracts from $P$. hexandrum measured by the FRAP assay. ASA was tested as a positive control. The data are the mean of triplicate measurements. Different letters on top of the column were considered significant at $\mathrm{p}<0.01$. 
Table 1 Separation and identification of ethyl acetate extract from P.hexandrum rhizome by GC-MS

\begin{tabular}{|c|c|c|c|c|c|c|}
\hline No. & RT & Name & Molecular Formula & molecular weight & Area & POA (\%) \\
\hline 1 & 16.56 & D-Allose & $\mathrm{C}_{6} \mathrm{H}_{10} \mathrm{O}_{5}$ & 162 & 68174247.68 & 1.85 \\
\hline 2 & 20.24 & Phthalic acid, diisobutyl ester (PADE) & $\mathrm{C}_{16} \mathrm{H}_{22} \mathrm{O}_{4}$ & 278 & 101990836.36 & 2.77 \\
\hline 3 & 22.44 & 1-Octadecanol & $\mathrm{C}_{18} \mathrm{H}_{38} \mathrm{O}$ & 270 & 5668336.18 & 0.15 \\
\hline 4 & 22.96 & Oleic Acid & $\mathrm{C}_{18} \mathrm{H}_{34} \mathrm{O}_{2}$ & 282 & 57474673.65 & 1.56 \\
\hline 5 & 23.17 & Octadecanoic acid & $\mathrm{C}_{18} \mathrm{H}_{36} \mathrm{O}_{2}$ & 284 & 15872716.84 & 0.43 \\
\hline 6 & 26.29 & 1,2-Benzenedicarboxylic acid, diisooctyl ester (BADE) & $\mathrm{C}_{24} \mathrm{H}_{38} \mathrm{O}_{4}$ & 390 & 82848910.41 & 2.25 \\
\hline 7 & 30.56 & 2,2'-Benzylidenebis(3-methylbenzofuran) & $\mathrm{C}_{24} \mathrm{H}_{20} \mathrm{~N}_{2} \mathrm{O}$ & 352 & 18407733.56 & 0.50 \\
\hline 8 & 35.04 & Campesterol & $\mathrm{C}_{28} \mathrm{H}_{48} \mathrm{O}$ & 400 & 8076867.21 & 0.22 \\
\hline$\underline{9}$ & 35.89 & Podophyllotoxin, deoxy (PODD) & $\mathrm{C}_{22} \mathrm{H}_{22} \mathrm{O}_{7}$ & 398 & 758866242.2 & 20.59 \\
\hline 10 & 37.19 & $\beta$-Sitosterol & $\mathrm{C}_{29} \mathrm{H}_{50} \mathrm{O}$ & 414 & 59476314.62 & 1.61 \\
\hline 11 & 38.05 & $\begin{array}{l}\text { Naphtho[2,3-c]furan-1(3H)-one,4-(3,4-dimethoxyphenyl)-3a,4,9,9a- } \\
\text { tetrahydro-6,7-dimethoxy-, [3aR-(3a?4?9a?]- }\end{array}$ & $\mathrm{C}_{22} \mathrm{H}_{24} \mathrm{O}_{6}$ & 384 & 24682996.63 & 0.67 \\
\hline 12 & 40.77 & Podophyllotoxin (Podofilox) (POD) & $\mathrm{C}_{22} \mathrm{H}_{22} \mathrm{O}_{8}$ & 414 & 2484773776 & 67.41 \\
\hline
\end{tabular}

\section{Evaluation of antioxidant capacity}

Figure 5 and 6 show antioxidant capacity of the six components identified from the extracts by using the DPPH and FRAP assays at the same concentration of $500 \mu \mathrm{M}$. The $\mathrm{IC}_{50}$ and FRAP values of PADE, BADE, Polyneuridine, PODD, $\beta$-Sitosterol, and POD were $22.49 \pm 0.60$ and $1062.5 \pm 23.39 \mu \mathrm{M}, 16.32 \pm 0.67$ and $1025.00 \pm 9.24 \mu \mathrm{M}, 13.37 \pm 0.35$ and $2404.32 \pm$ $36.88 \mu \mathrm{M}, 9.61 \pm 0.81$ and $2923.98 \pm 21.89 \mu \mathrm{M}, 32.43 \pm 0.81$ and $891.37 \pm 22.14 \mu \mathrm{M}, \quad 9.98 \pm 0.24$ and $2847.27 \pm$ $14.82 \mu \mathrm{M}$, respectively. Both of the tested statistics of $\mathrm{IC}_{50}$ and FRAP values showed that PODD, POD and Polyneuridine had greater antioxidant capacity than the positive control ASA $(60.78 \pm 1.22$ and $1267.5 \pm$ $30.24 \mu \mathrm{M})(p<0.01)$.

\section{Discussion}

Podophyllum contained 4-20\% of podophyllum resin, which is the source of POD [24,25]. Giri et al. [3] reported that Podophyllotoxin is commonly extracted from P.hexandrum that contains $6-12 \%$ of resin, of which the concentration of podophyllotoxin is around 40\%. Chawla et al. [26] reported that polyphenols and lignans were rich in P.hexandrum rhizome, which revealed several bioactivities of direct relevance to radioprotection.

In this work, about 16 kinds of reactive oxygen components were identified by GC-MS, some of which have been preliminarily studied for antioxidant capacity or identified from other plants. Zhang et al. [27] and Jin et al. [28] reported that POD derivatives had strong

Table 2 Separation and identification of ethanol extract from P.hexandrum rhizome by GC-MS

\begin{tabular}{|c|c|c|c|c|c|c|}
\hline No. & RT & Name & Molecular formula & Molecular weight & Area & POA (\%) \\
\hline 1 & 14.25 & d-Gala--ido-octonic amide & $\mathrm{C}_{8} \mathrm{H}_{17} \mathrm{NO}_{8}$ & 255 & 651876.57 & 0.75 \\
\hline 2 & 16.94 & Sucrose & $\mathrm{C}_{12} \mathrm{H}_{22} \mathrm{O}_{11}$ & 342 & 2221794.92 & 2.55 \\
\hline 3 & 20.75 & Phthalic acid, diisobutyl ester (PADE) & $\mathrm{C}_{16} \mathrm{H}_{22} \mathrm{O}_{4}$ & 278 & 1067190.30 & 1.23 \\
\hline 4 & 21.12 & 9-Hexadecenoic acid & $\mathrm{C}_{16} \mathrm{H}_{30} \mathrm{O}_{2}$ & 254 & 577281.13 & 0.66 \\
\hline 5 & 21.81 & n-Hexadecanoic acid & $\mathrm{C}_{16} \mathrm{H}_{32} \mathrm{O}_{2}$ & 256 & 4151490.41 & 4.77 \\
\hline 6 & 22.04 & Hexadecanoic acid, ethyl ester & $\mathrm{C}_{18} \mathrm{H}_{36} \mathrm{O}_{2}$ & 284 & 2383067.34 & 2.74 \\
\hline 7 & 22.81 & Retinol & $\mathrm{C}_{20} \mathrm{H}_{30} \mathrm{O}$ & 286 & 660693.34 & 0.76 \\
\hline 8 & 23.64 & 9,12-Octadecadienoic acid, ethyl ester & $\mathrm{C}_{20} \mathrm{H}_{36} \mathrm{O}_{2}$ & 308 & 2368466.98 & 2.72 \\
\hline$\underline{9}$ & 23.82 & Octadec-9-enoic acid & $\mathrm{C}_{18} \mathrm{H}_{34} \mathrm{O}_{2}$ & 282 & 1549676.99 & 1.78 \\
\hline 10 & 26.52 & Hexadecanoic acid, 2-(octadecyloxy) ethyl ester & $\mathrm{C}_{36} \mathrm{H}_{72} \mathrm{O}_{3}$ & 552 & 1112593.91 & 1.28 \\
\hline 11 & 26.78 & 1,2-Benzenedicarboxylic acid, diisooctyl ester (BADE) & $\mathrm{C}_{24} \mathrm{H}_{38} \mathrm{O}_{4}$ & 390 & 6141357.57 & 7.05 \\
\hline 12 & 35.99 & Podophyllotoxin, deoxy (PODD) & $\mathrm{C}_{22} \mathrm{H}_{22} \mathrm{O}_{7}$ & 398 & 18255949.66 & 20.97 \\
\hline 13 & 37.60 & $\beta$-Sitosterol & $\mathrm{C}_{29} \mathrm{H}_{50} \mathrm{O}$ & 414 & 1063814.09 & 1.22 \\
\hline 14 & 39.00 & Ethyl iso-allocholate & $\mathrm{C}_{26} \mathrm{H}_{44} \mathrm{O}_{5}$ & 436 & 673221.09 & 0.77 \\
\hline 15 & 40.01 & Polyneuridine & $\mathrm{C}_{21} \mathrm{H}_{24} \mathrm{~N}_{2} \mathrm{O}_{3}$ & 352 & 24387006.54 & 28.01 \\
\hline 16 & 40.23 & Podophyllotoxin (Podofilox) (POD) & $\mathrm{C}_{22} \mathrm{H}_{22} \mathrm{O}_{8}$ & 414 & 19787459.99 & 22.73 \\
\hline
\end{tabular}




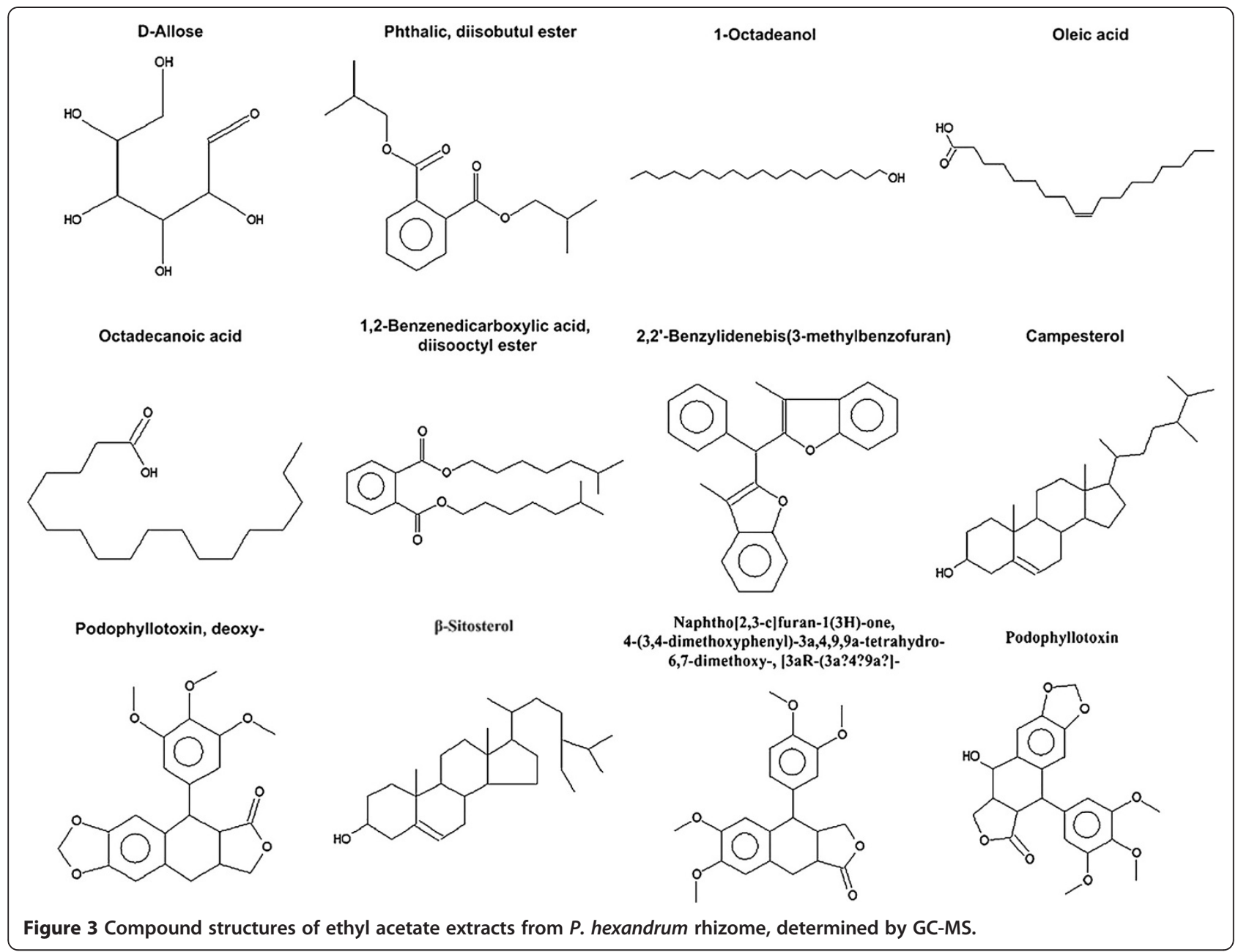

antioxidative activities. $\mathrm{Ng}$ et al. [29] revealed that PODD could inhibit lipid peroxidation in brain and kidney homogenates, and the compound had antioxidant effects. Besides antioxidant potential, $\beta$-Sitosterol exhibited a protective action against $\mathrm{DMH}$-induced depletion of antioxidants, such as catalase, superoxide dismutase, and glutathione peroxidase [30]. Zhao et al. [31] identified PADE from traditional Chinese medicines of pungent flavor and cool nature by GC-MS. Lin et al. [32] isolated BADE from the volatile components of Eclipta prostrate by GC-MS. The six components PADE, BADE, Polyneuridine, PODD, $\beta$-Sitosterol, and POD presented high POA (pereentage of area) in the extracts, and the highest POAs of PODD, POD and Polyneuridine were 20.97, 67.41 and $28.01 \%$ in the rhizome, respectively, these results suggest that the components PODD, POD and Polyneuridine are very critical for the antioxidant capacity.

Although the POAs of other components in the ethyl acetate and ethanol extracts are relatively small, antioxidant capacity was also reported in other plant extracts, such as D-allose [33], Dibutyl phthalate [34,35], nHexadecanoic acid [33-36], Oleicacid [36,37], Octadecanoic acid [37], Octadec-9-enoic acid [32], Campesterol [38,39], Retinol [40]. So far, both PADE and BADE have not been reported on the antioxidant capacity. Other active components might be present in the extracts and should be under further investigation.

\section{Conclusions}

The rhizome extracts had greater antioxidant capacity than the petiole extracts in DPPH and FRAP assays. About 16 kinds of reactive oxygen components were identified by GC-MS in the extracts of P.hexandrum, this was the first to report PADE and BADE from a plant product and further study the antioxidant capacity of the identified components PADE, BADE, Polyneuridine, PODD, $\beta$-Sitosterol, and POD. The results of tested data and statistical analysis proved that the extracts from $P$. hexandrum had strong antioxidant capacity, and the PODD, POD and Polyneuridine played an important role. Based on the above data it can be recommended as 


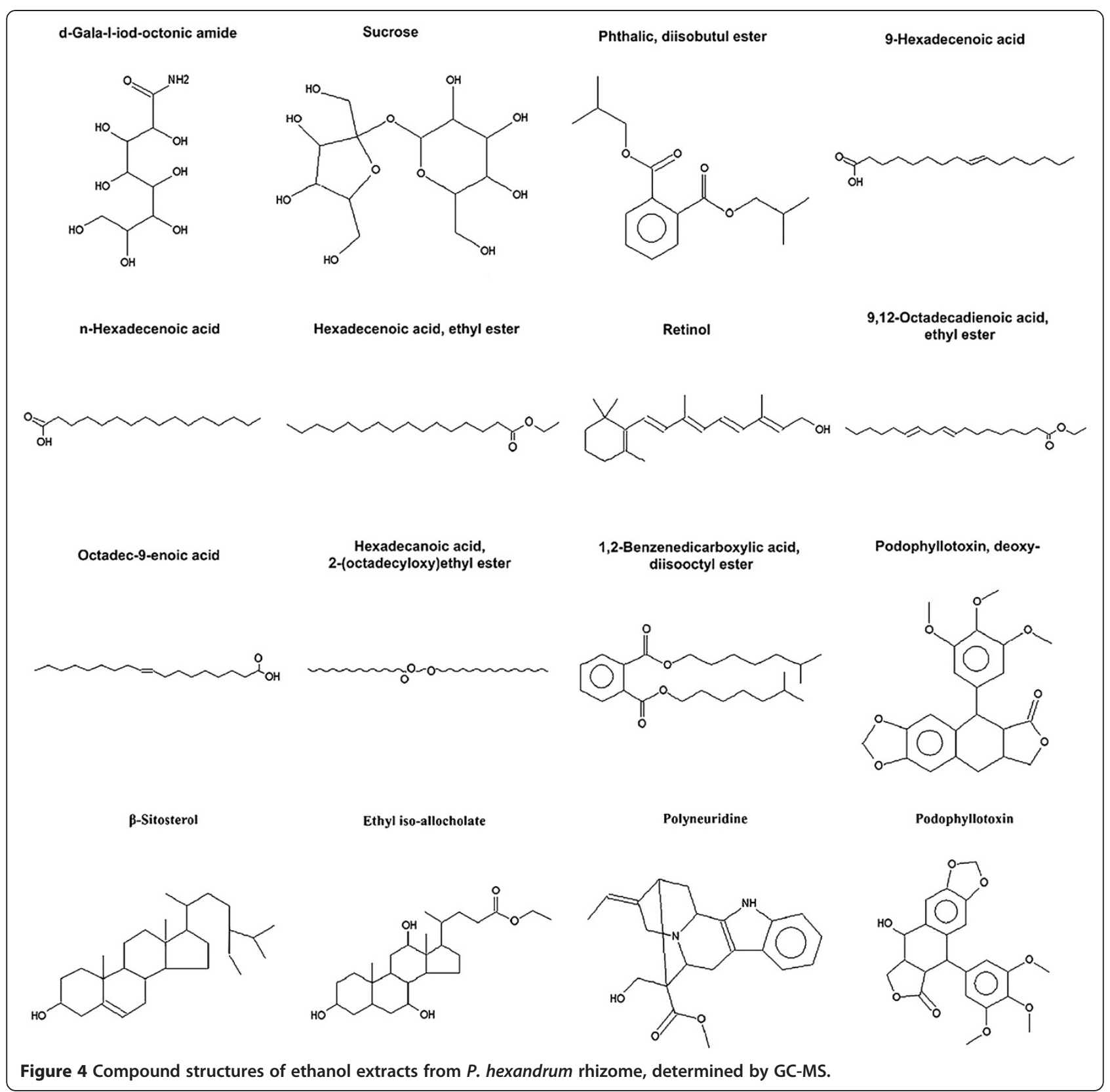

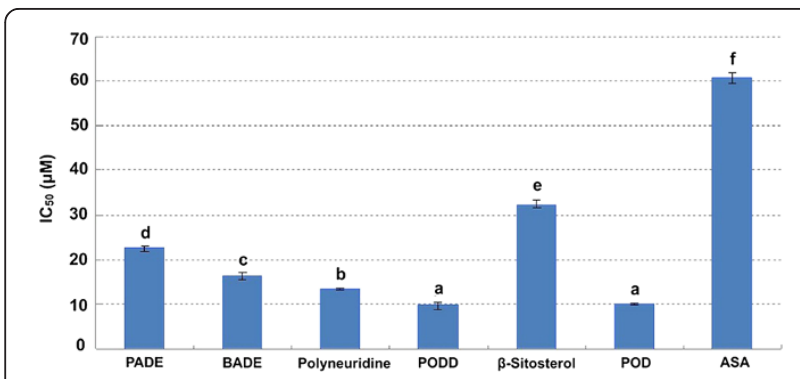

Figure $5 \mathrm{IC}_{50}$ of the 6 components in the extracts from

P. hexandrum rhizome. ASA was tested as a positive control. The data are the mean of triplicate measurements. Different letters on top of the column were considered significant at $p<0.01$.

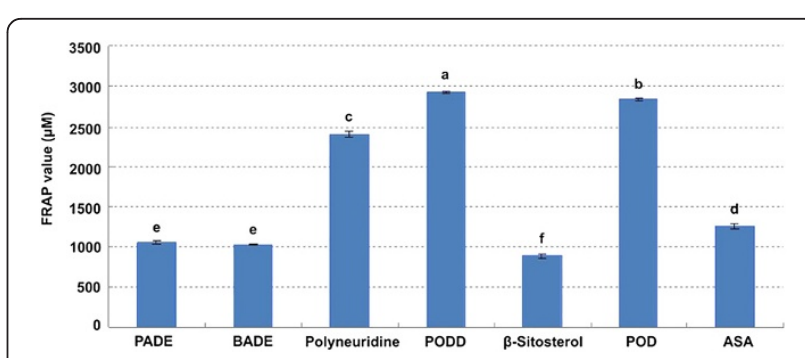

Figure 6 FRAP value of the 6 components in the extracts from P. hexandrum rhizome. ASA was tested as a positive control. The data are the mean of triplicate measurements. Different letters on top of the column were considered significant at $p<0.01$. 
an alternative plant material of antioxidant and radical scavenging activity.

\section{Competing interests}

The authors declare that they have no competing interests.

\section{Authors' contributions}

MFL designated the study, performed the statistical analysis and drafted the manuscript. LLZ and TTL participated in the extraction and the antioxidant assays. DLY did the isolation and structure elucidation part and helped in manuscript editing. WL has made substantial contribution to conception and design, and revising the manuscript for intellectual content. All authors read and approved the final manuscript.

\section{Acknowledgements}

We are grateful for the financial support of Doctoral Fund of Ministry of Education of the People's Republic of China (No.20096202110006), and the SRTP of Gansu Agricultural University (No.20120810 and No.20120818). We thank Yongzhong Huang, College of Chemistry and Chemical Engineering, Lanzhou University, P.R.China, for the GC-MS analysis. We also thank Jinghua $\mathrm{Li}$ and Jing Zhang, College of Life Science and Technology, Gansu Agricultural University, P.R.China, for collecting the plant materials.

Received: 11 October 2012 Accepted: 19 December 2012

Published: 22 December 2012

\section{References}

1. Chen YH: Research on resource of Podophyllum category in China. Yao Xue Xue Bao 1979, 14:101-107.

2. Farkya S, Bisaria VS, Srivastava AK: Biotechnological aspects of the production of the anticancer drug podophyllotoxin. Appl Microbiol Biotechnol 2004, 65:504-519.

3. Giri A, Narasu ML: Production of podophyllotoxin from Podophyllum hexandrum: a potential natural product for clinically useful anticancer drugs. Cytotechnology 2000, 34:17-26.

4. MayeauX EJJ, Harper MB, Barksdale W, Pope JB: Noncervical human papillomavirus genital infections. Am Fam Physician 1995, 52:1137-1150.

5. White DJ, Billingham C, Chapman S, Drake S, Jayaweera D, Jones S, Opaneye A, Temple C: Podophyllin $0.5 \%$ or $2.0 \%$ v podophyllotoxin $0.5 \%$ for the self treatment of penile warts: a double blind randomized study. Genitourin Med 1997, 73:184-187.

6. Stahelin HF, von-Wartburg A: From the chemical and biological route from podophyllotoxin glucoside to etoposide, ninth Cain memorial award lecture. Cancer Res 1991, 51:5-15.

7. Airi S, Rawal RS, Dhar U, Purohit AN: Population studies on Podophyllum hexandrum Royle-a dwindling medicinal plant of the Himalaya. Plant Genet Resour Newsl 1997, 110:29-34.

8. Zhao Y, Wang C, Wu Z, Fang J, Zhu L: Synthesis and antitumor activity of novel aroylthiourea derivatives of podophyllotoxin. Invest New Drugs 2012, 30:17-24.

9. Chen SW, Wang YH, Jin Y, Tian X, Zheng YT, Luo DQ, Tu YQ: Synthesis and anti-HIV-1 activities of novel podophyllotoxin derivatives. Bioorg Med Chem Lett 2007, 17:2091-2095.

10. Zhang XY, Li WG, Wu YJ, Tian X: Antioxidative and antitumor activity of derivatives of 4-beta-amino-4'-demethylepipodophyllotoxin and their structure-activity relationship. Pharmazie 2007, 62:432-438.

11. Li MF, Li W, Yang DL, Sun P: The dormancy mechanism and bioactivity of hydroquinone extracted from Podophyllum hexandrum Royle seed. Electr J Biol 2009, 5:11-16.

12. Mot AC, Silaghi-Dumitrescu R, Sarbu C: Rapid and effective evaluation of the antioxidant capacity of propolis extracts using DPPH bleaching kinetic profiles, FT-IR and UV-vis spectroscopic data. J Food Composit Anal 2011, 24:516-522.

13. Frankel EN: In search of better methods to evaluate natural antioxidants and oxidative stability in food lipids. Trends Food Sci Technol 1993, 4:220-225.

14. Ou B, Huang D, Hampsch-Woodill M, Flanagan JA, Deemer EK: Analysis of antioxidant activities of common vegetables employing oxygen radical absorbance capacity (ORAC) and ferric reducing antioxidant power (FRAP) assays: a comprehensive study. J Agric Food Chem 2002, 50:3122-3128
15. Arnao MB: Some methodological problems in the determination of antioxidant activity using chromogen radicals: a practical case. Trends Food Sci Technol 2000, 11:419-421.

16. Ramadan MF, Kroh LW, Morsel JT: Radical scavenging activity of black cumin (Nigella sativa L.), coriander (Coriandrum sativum L.), and niger (Guizotia abyssinica Cass.) crude seed oils and oil fractions. J Agric Food Chem 2003, 51:6961-6969.

17. Nencini C, Menchiari A, Franchi GG, Micheli L: In vitro antioxidant activity of aged extracts of some Italian Allium species. Plant Foods Hum Nutr 2011, 66:11-16.

18. MacDonald-Wicks LK, Wood LG, Garg ML: Methodology for the determination of biological antioxidant capacity in vitro: A review. J Sci Food Agric 2006, 86:2046-2056.

19. Prior RL, Wu X, Schaich K: Standardized methods for the determination of antioxidant capacity and phenolics in foods and dietary supplements. J Agric Food Chem 2005, 53:4290-4302.

20. Foti MC, Daquino C, Geraci C: Electron-transfer reaction of cinnamic acids and their methyl esters with the DPPH radical in alcoholic solutions. J Org Chem 2004, 69:2309-2314.

21. Brand-Williams W, Cuvelier ME, Berset C: Use of a free radical method to evaluate antioxidant activity. Lebensm Wiss u Technol 1995, 28:25-30.

22. Benzie IFF, Strain Jj: The ferric reducing ability of plasma (FRAP) as a measure of "antioxidant power":The FRAP assay. Anal Biochem 1996, 239:70-76.

23. Tsao R, Yang R, Young JC: Antioxidant isoflavones in osage orange, Maclura pomifera (Raf.) Schneid. J Agric Food Chem 2003, 51:6445-6451.

24. Drew SE, Conway SJ, Jenning P, Helliwell K: Determination of the aryltetralin lignan content of podophyllum resins and roots/rhizomes. J Pharm Pharmacol 1987, 39:738-739.

25. Purohit MC, Bahuguna R, Maithani UC, Purohit AN, Rawat MSM: Variation in podophylloresin and podophyllotoxin contents in different populations of Podophyllum hexandrum. Curr Sci 1999, 77:1078-1080.

26. Chawla R, Arora R, Kumar R, Sharma A, Prasad J, Singh S, Sagar R, Chaudhary P, Shukla S, Kaur G: Antioxidant activity of fractionated extracts of rhizomes of high-altitude Podophyllum hexandrum: Role in radiation protection. Mol Cell Biochem 2005, 273:193-208.

27. Zhang JQ, Zhang ZW, Hui L, Chen SW, Tian X: Novel semisynthetic spinlabeled derivatives of podophyllotoxin with cytotoxic and antioxidative activity. Bioorg Med Chem Lett 2010, 20:983-986.

28. Jin $Y$, Chen SW, Tian $X$ : Synthesis and biological evaluation of new spin-labeled derivatives of podophyllotoxin. Bioorg Med Chem 2006, 14:3062-3068.

29. Ng TB, Liu F, Wang ZT: Antioxidative activity of natural products from plants. Life Sci 2000, 66:709-723.

30. Baskar AA, Al Numair KS, Gabriel PM, Alsaif MA, Muamar MA, Ignacimuthu S: $\beta$-sitosterol prevents lipid peroxidation and improves antioxidant status and histoarchitecture in rats with 1,2-dimethylhydrazine-induced colon cancer. J Med Food 2012, 15:335-343.

31. Zhao C, Zeng Y, Wan M, Li R, Liang Y, Li C, Zeng Z, Chau FT: Comparative analysis of essential oils from eight herbal medicines with pungent flavor and cool nature by GC-MS and chemometric resolution methods. J Sep Sci 2009, 32:660-670.

32. Lin $X H, W u ~ Y B$, Lin $S$, Zeng JW, Zeng PY, Wu JZ: Effects of volatile components and ethanolic extract from Eclipta prostrata on proliferation and differentiation of primary osteoblasts. Molecules 2010, 15:241-250.

33. Ishihara Y, Katayama K, Sakabe M, Kitamura M, Aizawa M, Takara M, Itoh K: Antioxidant properties of rare sugar D-allose: Effects on mitochondrial reactive oxygen species production in Neuro2A cells. J Biosci Bioeng 2011, 112:638-642.

34. Yang J, Qu Z, Xiao YL, Qiu GF, Zhang T, Wu ZY, He XR, Hu XM: Chemical composition and antioxidant activity of the essential oil of endemic Viola tianshanica. Nat Prod Res 2011, 25:1635-1640.

35. Zhang W, Shen H, Ma L, Shen B, Xu Z, Wang X: Differential expression of peroxiredoxin 6 in fetal rat testis following in utero exposure to di(n-butyl) phthalate. Toxicology 2007, 240:86-95.

36. Bowyer JN, Rout-Pitt N, Bain PA, Stone DA, Schuller KA: Dietary fish oil replacement with canola oil up-regulates glutathione peroxidase 1 gene expression in yellowtail kingfish (Seriola lalandi). Comp Biochem Physiol B Biochem Mol Biol 2012, 162:100-106.

37. Tamokou JD, Simo Mpetga DJ, Keilah Lunga P, Tene M, Tane P, Kuiate JR: Antioxidant and antimicrobial activities of ethyl acetate extract, fractions 
and compounds from stem bark of Albizia adianthifolia (Mimosoideae). BMC Complement Altern Med 2012, 12:99.

38. Menezes EW, Tadini CC, Tribess TB, Zuleta A, Binaghi J, Pak N, Vera G, Dan MC, Bertolini AC, Cordenunsi BR, Lajolo FM: Chemical composition and nutritional value of unripe banana flour (Musa acuminata, var. Nanicão). Plant Foods Hum Nutr 2011, 66:231-237.

39. Rudell DR, Buchanan DA, Leisso RS, Whitaker BD, Mattheis JP, Zhu Y, Varanasi V: Ripening, storage temperature, ethylene action, and oxidative stress alter apple peel phytosterol metabolism. Phytochemistry 2011, 72:1328-1340

40. Morelli LL, Prado MA: Extraction optimization for antioxidant phenolic compounds in red grape jam using ultrasound with a response surface methodology. Ultrason Sonochem 2012, 19:1144-1149.

doi:10.1186/1472-6882-12-263

Cite this article as: Li et al.: Biochemical composition and antioxidant capacity of extracts from Podophyllum hexandrum rhizome.

BMC Complementary and Alternative Medicine 2012 12:263.

\section{Submit your next manuscript to BioMed Central and take full advantage of:}

- Convenient online submission

- Thorough peer review

- No space constraints or color figure charges

- Immediate publication on acceptance

- Inclusion in PubMed, CAS, Scopus and Google Scholar

- Research which is freely available for redistribution 